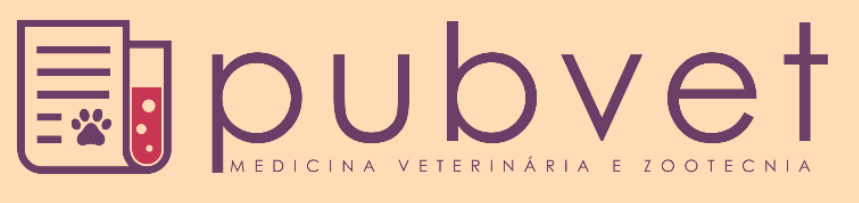

https://doi.org/10.31533/pubvet.v14n7a602.1-3

\title{
Raiva bovina: revisão
}

\author{
Alexandre Luiz Alves ${ }^{1}$, Ana Vitória Ferreira Borges ${ }^{1}{ }^{\bullet}$, Kaio Batista dos Reis ${ }^{1}{ }^{\ominus}$, Lara Cristina de \\ Souza e Silva ${ }^{1} \bullet$, Leonardo José Ribeiro ${ }^{1}$, Marcos Antonio Rodrigues Pereira ${ }^{1}$, Rodrigo Batista Jacó ${ }^{1}$, \\ Wesley Fernandes Silva ${ }^{1}$, Alexandre Lifonso de $\operatorname{Souza}^{10}$, Cláudio Costa ${ }^{2} \bullet$, Laryssa Freitas Ribeiro ${ }^{2 *} \bullet$
}

${ }^{1}$ Alunos do curso de Medicina Veterinária do $2^{\circ}$ período do Centro Universitário Mário Palmério, Monte Carmelo, Minas Gerais, Brasil ${ }^{2}$ Professores do curso de Medicina Veterinária do Centro Universitário Mário Palmério, Monte Carmelo, Minas Gerais, Brasil

*Autor para correspondência, E-mail: laryssaribeiro84@gmail.com

Resumo. Os bovinos desempenham um papel importante na transmissão da raiva em todo o mundo. Além da grave situação de raiva humana, a disseminação do vírus da raiva por bovinos nos últimos anos causou surtos de raiva em ovelhas e porcos, mostrando que há uma ameaça crescente a outros animais domésticos. O objetivo do estudo foi fazer uma breve revisão sobre a doença, abordando os aspectos clínicos, patológicos e controle da doença, gerando informações para acadêmicos, profissionais e produtores rurais.

Palavras chave: bovinocultura leiteira, Lyssavirus, zoonoses

\section{Bovine rabies: review}

Abstract. Cattle is an important role in the transmission of rabies worldwide. In addition to the serious human rabies situation, the spread of the rabies virus by cattle in recent years has caused outbreaks of rabies in sheep and pigs, showing that there is an increasing threat to other domestic animals. The objective of the study was to make a brief review of the disease, addressing the clinical, pathological and disease control aspects, generating information for academics, professionals and rural producers.

Keywords: dairy cattle, Lyssavirus, zoonoses

\section{Introdução}

A raiva é uma zoonose importante para a saúde pública, a qual ocasiona grandes perdas econômicas para a pecuária (Morato et al., 2011). De acordo com Reis et al. (2005), a doença mata 100.000 bovinos por ano na América Latina e gera perdas de cerca de 30 milhões de dólares.

A raiva é uma doença infectocontagiosa, causada por um vírus, em que quase $100 \%$ dos casos são fatais (Radostits et al., 2010). Esse vírus pertence a família Rhabdoviridae e gênero Lyssavirus, seu material genético é o ácido ribonucleico (RNA), sendo ele altamente neurotrópico (Smith, 2006). A raiva é uma enfermidade neurológica viral, invariavelmente fatal, mais frequente em bovinos no Brasil (Lima et al., 2005). Há duas variantes do vírus detectadas no Brasil: (1) uma associada ao ciclo urbano, isolada de cães, gatos e humanos e que causa a forma furiosa de raiva; (2) outra associada ao ciclo silvestre da doença, isolada de bovinos e morcegos e que causa a forma paralítica de raiva (Heinemann et al., 2002; Ito et al., 2001; Kobayashi et al., 2006).

A principal forma de transmissão ocorre quando os vírus da raiva, existente na saliva do animal infectado, penetra no organismo pela pele ou mucosas, por mordedura, arranhadura ou lambedura, mesmo não existindo necessariamente agressões. É possível também a transmissão via aérea, por meio da inalação de aerossóis ou transplante de córneas (Costa, 2000). 
Após nova replicação, os vírus, via neurogênica e de forma centrifuga, disseminam-se por todo o organismo, principalmente sistema nervoso central e glândulas salivares (Kotait et al., 2007; Scheffer et al., 2007). Após período de incubação, inicia-se os sintomas, os quais são classificados por três fases distintas: a fase prodrômica, a fase excitativa e a fase paralítica. A fase prodrômica é a fase de mais curta duração ( 2 a 3 dias), caracterizada pelos sinais iniciais como hiper excitabilidade aos estímulos externos, como luz, ruídos, deslocamento de ar etc. Já na fase excitativa, que pode durar de três a sete dias, os sintomas observados são os mais facilmente associados à doença, a hiper excitabilidade e agressividade. Por último, a fase paralítica caracteriza-se por paralisia progressiva que parte dos membros posteriores em direção à cabeça. A morte, por asfixia, ocorre quando a paralisia chega à musculatura respiratória (MS \& FNS, 1998).

Assim, sintomas como dificuldade de locomoção, cambaleante do membro posterior, dificuldade de deglutição, diminuição de apetite, sialorreia, andar cambaleante, paralisia flácida e incapacidade em se levantar são comuns na casuística da Clínica de Bovinos (Oliveira dos Campinhos, Santo Amaro, Bahia), Universidade Federal da Bahia, durante o período de janeiro de 1990 a dezembro de 1999 (Reis et al., 2005). Este mesmo trabalho, entretanto, demonstra baixa percentagens de outros sinais como retenção de fezes e urina; porém, também há relatos de relaxamento do esfíncter anal, audição diminuída, reflexo pupilar diminuído, sensibilidade cutânea diminuída e em alguns casos, aumentada. Porém, vale ressaltar que os sintomas de maior prevalência são aqueles relacionados com sintomatologia nervosa.

A Instrução Normativa $n^{\circ} 5$ de $1^{\circ}$ de março de 2002 preconiza que a vacinação dos herbívoros seja realizada com vacina contendo vírus inativado, na dosagem de $2 \mathrm{ml}$ por animal independentemente da idade, sendo aplicada por via subcutânea ou intramuscular. A vacinação compulsória é recomendada quando da ocorrência de focos da doença e deve ser adotada preferencialmente em bovídeos e equídeos, com idade igual ou superior a três meses. Para efeito da revacinação, considera-se que a duração da imunidade conferida pela vacina será no máximo de 12 meses (Brasil, 2002). Apesar disso, o grande número de casos de raiva positiva em animais vacinados concorda com os resultados encontrados por Rondon et al. (1995) que descreveram valores em torno de $42,11 \%$ de animais positivos, vacinados para a raiva.

No Brasil, a raiva dos herbívoros pode ser considerada endêmica e em graus diferenciados, de acordo com a região. Os principais fatores que contribuem para que a raiva no Brasil dissemine-se ainda de forma insidiosa e preocupante nos herbívoros domésticos são o aumento da oferta de alimento, representado pelo significativo crescimento dos rebanhos; a ocupação desordenada, caracterizada por macro modificações ambientais, como desmatamento, construção de rodovias e de hidroelétricas, que alteraram o ambiente em que os morcegos viviam, obrigando-os a procurar novas áreas e outras fontes de alimentação; a oferta de abrigos artificiais, representados pelas construções, como túneis, cisternas, casas abandonadas, bueiros, fornos de carvão desativados e outros; e a atuação insatisfatória, em alguns estados brasileiros, na execução do Programa Estadual de Controle da Raiva dos Herbívoros (Novais \& Zappa, 2008).

Conforme dados oficiais do Ministério da Agricultura Pecuária e Abastecimento (MAPA, 2015) e estimativas de subnotificações, por ano, no Brasil, a doença mata em média 45.000 bovinos, provocando um prejuízo de até 15 milhões de dólares para o país, esse número representa metade dos bovinos mortos pela doença na América Latina. Cabe ao proprietário notificar a suspeita de casos de raiva em herbívoros ao Serviço Veterinário Oficial, bem como a presença de animais apresentando mordeduras por morcegos hematófagos, ou ainda, informar a existência de abrigos desses morcegos. A não notificação coloca em risco à saúde dos rebanhos da região e dos seres humanos.

\section{Conclusão}

Os grandes prejuízos ocasionados pela raiva bovina se estendem tanto aos produtores e criadores do rebanho quanto às indústrias que utilizam a carne como matéria-prima. Ademais, por ser uma zoonose, torna-se um risco à saúde humana, não só por sua evolução drástica e letal, como também por seu elevado custo social e econômico. Sendo assim, é indispensável o estudo a respeito dessa doença que acomete os rebanhos e de importância em saúde pública. 


\section{Referências bibliográficas}

Costa, W. A. (2000). Manual de profilaxia da raiva humana. Instituto Pasteur.

Heinemann, M. B., Fernandes-Matioli, F. M. C., Cortez, A., Soares, R. M., Sakamoto, S. M., Bernardi, F., Ito, F. H., Madeira, A. M. B. N., \& Richtzenhain, L. J. (2002). Genealogical analyses of rabies virus strains from Brazil based on $\mathrm{N}$ gene alleles. Epidemiology \& Infection, 128(3), 503-511. DOI: https://doi.org/10.1017/S095026880200688X

Ito, M., Arai, Y. T., Itou, T., Sakai, T., Ito, F. H., Takasaki, T., \& Kurane, I. (2001). Genetic characterization and geographic distribution of rabies virus isolates in Brazil: identification of two reservoirs, dogs and vampire bats. Virology, 284(2), 214-222.

Kobayashi, Y., Ogawa, A. I., Sato, G. O., Sato, T., Itou, T., Samara, S. I., Carvalho, A. A. B., Nociti, D. P., Ito, F. H., \& Sakai, T. (2006). Geographical distribution of vampire bat-related cattle rabies in Brazil. Journal of Veterinary Medical Science, 68(10), 1097-1100. DOI: https://doi.org/10.1292/jvms.68.1097

Kotait, I., Carrieri, M. L., Carnieli Júnior, P., Castilho, J. G., Oliveira, R. de N., Macedo, C. I., Ferreira, K. C. S., \& Achkar, S. M. (2007). Reservatórios silvestres do vírus da raiva: um desafio para a saúde pública. Boletim Epidemiológico Paulista, 4(40), 2-8.

Lima, E. F., Riet-Correa, F., Castro, R. S., Gomes, A. A. B., \& Lima, F. S. (2005). Sinais clínicos, distribuição das lesões no sistema nervoso e epidemiologia da raiva em herbívoros na região Nordeste do Brasil. Pesquisa Veterinária Brasileira, 25(4), 250-264. DOI: http://dx.doi.org/10.1590/S0100-736X2005000400011

MAPA (2020) - Ministério da Agricultura, Pecuária e Abastecimento. Revisão sobre a Raiva. Disponível em: <http://www.agricultura.gov.br/assuntos/sanidade-animal-e-vegetal/saudeanimal/programas-de-saude-animal/raiva-dos-herbivoros-e-eeb/RevisosobreRaiva2017.pdf/view>. Acesso em: 24 janeiro 2020.

MS \& FNS. (1998). Centro Nacional de Epidemiologia. Guia de vigilância epidemiológica. Gráfica e Editora Teixeira. Cap. 5.26.

Morato, F., Ikuta, C. Y., \& Ito, F. H. (2011). Raiva: uma doença antiga, mas ainda atual. Revista de Educação Continuada Em Medicina Veterinária e Zootecnia Do CRMV-SP, 9(3), 20-29. DOI: https://doi.org/10.36440/recmvz.v9i3.173

Novais, B. A. F., \& Zappa, V. (2008). Raiva em bovinos-revisão de literatura. Revista Científica Eletrônica de Medicina Veterinária Da Faculdade de Medicina Veterinária e Zootecnia de Garça, 10.

Radostits, O. M., Gay, C. C., Blood, D. C., Hinchcliff, K. W., \& McKenzie, R. A. (2010). Clínica Veterinária: um tratado de doenças dos bovinos, ovinos, suínos, caprinos e eqüinos (Vol. 1). Guanabara Koogan.

Reis, M. C., Costa, J. N., Peixoto, A. P. C., Figueiredo, L. J. C., Menezes, R. V., M Ferreira, M., \& SÁ, J. E. U. (2005). Aspectos clínicos e epidemiológicos da raiva bovina apresentados na casuística da Clínica de Bovinos (Oliveira dos Campinhos, Santo Amaro, Bahia), Universidade Federal da Bahia, durante o período de janeiro de 1990 a dezembro de 1999 (Relato de caso). Revista Brasileira de Saúde e Produção Animal, 4(1), 12-17.

Rondon, E. S., Bastos, P. V, Silva, D. A., \& Piccinini, R. S. (1995). Estudo comparativo da sintomatologia clínica de bovinos suspeitos de raiva. Revista Brasileira de Medicina Veterinária, 17, 253-256.

Scheffer, K. C., Carrieri, M. L., Albas, A., Santos, H. C. P., Kotait, I., \& Ito, F. H. (2007). Rabies virus in naturally infected bats in the State of São Paulo, Southeastern Brazil. Revista de Saúde Pública, 41, 389-395.

Smith, M. O. (2006). Tratado de medicina interna de grandes animais (Vol. 1). Manole.

Recebido: 12 de março, 2020. Aprovado: 14 de abril, 2020.

Disponível online: 21 julho, 2020.
Licenciamento: Este artigo é publicado na modalidade Acesso Aberto sob a licença Creative Commons Atribuição 4.0 (CC-BY 4.0), a qual permite uso irrestrito, distribuição, reprodução em qualquer meio, desde que o autor e a fonte sejam devidamente creditados. 